\title{
Relation between serum progranulin, inflammatory markers and visceral fat in childhood obesity
}

\author{
Nagwa Abdallah Ismail ${ }^{1}$, Shadia Ragab ${ }^{2}$, Abeer Nour Eldin Abd El Baky ${ }^{1}$, Mona Hamed ${ }^{2}$, \\ Dina F. Ayoub ${ }^{2}$ \\ ${ }^{1}$ Pediatrics' Department, National Research Center, Cairo, Egypt \\ ${ }^{2}$ Department of Clinical Pathology, National Research Center, Cairo, Egypt \\ Email:nagwa_abdallah@yahoo.com
}

Received 9 October 2013; revised 12 November 2013; accepted 26 November 2013

Copyright (C) 2013 Nagwa Abdallah Ismail et al. This is an open access article distributed under the Creative Commons Attribution License, which permits unrestricted use, distribution, and reproduction in any medium, provided the original work is properly cited.

\begin{abstract}
Aim: To study serum progranulin (PGRN) level in children with obesity and its relationship to inflamamatory markers and visceral fat. Methods: Fifty obese children and 50 controls aged 10 - 18 years were recruited. Demographic, anthropometric and biochemical features were collected according to a standard protocol. Serum progranulin levels, serum IL-6 and hsCRP were measured using ELISA. Insulin resistance was calculated by the homeostasis model (HOMA-IR) using the following formula: HOMA-IR $=$ fasting insulin $(\mathrm{mU} / \mathrm{L}) \times$ fasting glucose $(\mathrm{mmoL} / \mathrm{L}) /$ 22.5. The maximum visceral fat thickness (VFT) and the minimum subcutaneous fat thickness (SFT) were measured by ultrasonography. Results: In the obese group, a significant increase was found in serum PGRN (48.87 $\pm 42.33 \mathrm{ng} / \mathrm{mL})$ compared to control group (30.18 $\pm 23.82 \mathrm{ng} / \mathrm{mL})$. Progranulin correlated significantly with VFT $(r=0.475)$, IL6 $(r=0.368)$, $\operatorname{Insulin}(r=0.440)$ and HOMA-IR $(r=0.379)$. The mean serum progranulin in the high tertile VFT group was significantly higher than those in the low tertile and middle tertile groups $(P=0.030$ and $P=$ 0.039 respectively). VFT was highly positively correlated to progranulin, SFT, IL6, insulin, HOMA-IR and hsCRP (P $=0.001,0.000,0.001,0.001,0.003$ and 0.003). However, the correlation coefficient between SFT and progranulin was insignificant. Summary: we demonstrated for the first time that serum PGRN concentrations increased in Egyptian obese children. The concentrations of serum PGRN correlated closely with visceral fat and IL6. Conclusion: PGRN may contribute to the pathogenesis of chronic inflammation in obesity. It could be a novel marker of visceral fat in obesity. Thus PGRN could be a potential therapeutic target for management of chronic inflammation in obesity.
\end{abstract}

Keywords: Progranulin; Obesity; Visceral Fat; Insulin Resistance; IL6

\section{INTRODUCTION}

Childhood obesity has more than doubled in children and tripled in adolescents in the past 30 years [1]. Abdominal adiposity is a risk factor for obesity-related complications, and there is increasing evidence that abdominal adiposity may be a contributing factor to complications $[2,3]$. Inflammatory mediators have a surprising impact in obesity [4]. Fain, 2006 cited that human adipose tissue is a potent source of inflammatory interleukins plus other cytokines and that the majority of this release is due to the nonfat cells in the adipose tissue except for leptin and adiponectin that are primarily secreted by adipocytes [5].

Several factors including adipocyte hypertrophy, hypoxia and stresses in adipose tissue could either directly or as a sequence of patho-mechanisms induce an inflammatory process in adipose tissue. Obesity and inflammation are highly integrated processes in the pathogenesis of insulin resistance, diabetes, atherosclerosis, and non-alcoholic fatty liver disease [6]. Recent studies consistently support a hypoxia response in the adipose tissue in obese animals. The observations have led to formation of an exciting concept, adipose tissue hypoxia (ATH), in the understanding of major disorders associated with obesity. ATH may provide cellular mechanisms for chronic inflammation, macrophage infiltration, adiponectin reduction, leptin elevation, adipocyte death [7].

Progranulin (PRGN) is a novel marker of chronic inflammation in obesity which closely reflects omental adipose tissue macrophage infiltration. It is a secreted protein with important functions in several processes, including immune response and embryonic development [8]. Progranulin, also known as granulin, acrogranin, 
proepithelin, and PC cell-derived growth factor, is a 593-amino acid glycoprotein [8]. Progranulin gene can be found in adipose tissue, epithelial tissue, and gastrointestinal tract and reproductive organs [9]. A recent study showed that progranulin is an inducible protein in response to hypoxia or acidosis [10]. The greatest increases in progranulin occurred when hypoxia and acidosis were combined. Increased progranulin occurred at conditions of $\mathrm{pH}$ and hypoxia under which cell viability remained high [10]. Taken together, progranulin is an important molecule in inflammatory response and could therefore be involved in chronic subclinical inflammation associated with human obesity. To our knowledge, no previous studies have explored the potential links between visceral fat and PRGN in obese children. In this study, we aim to investigate the concentrations of serum progranulin in Egyptian obese children and its relationship to inflammatory markers and visceral fat.

\section{MATERIAL AND METHODS}

\subsection{Study Population}

We performed a cross-sectional study. The study protocol was approved by the Human Ethics Committee of National Research Center, and written informed consent was obtained from all children and their parents. WE enrolled 100 subjects: 50 non-obese children and 50 obese children. They were recruited from the Obesity Clinic at the NRC. All non-obese volunteers were agematched healthy subjects in good health and taking no medications. A child was obese if body mass index (BMI) $>95$ th percentile for age and gender percentile curves of growth for our population [11]. The studied group was classified into 2 groups according to body mass index: normal weight (BMI $18.5-24.9$ and obesity BMI $\geq 30$ $\mathrm{kg}=\mathrm{m}^{2}$ ).

Exclusion criteria: Patients with any of the following criteria were excluded from the study: hepatobiliary diseases, chronic liver diseases including viral hepatitis malignancies, ascites, medications known to cause hepatic steatosis (such as estrogens, corticosteroids, amiodarone, and valoprate; at present or within the last 2 years), anti-inflammatory drugs, inflammatory bowel disease, human immunodeficiency virus, renal diseases, hypothyroidism, Cushing syndrome or Turner syndrome, also obesity with mental retardation, such as Prader-Willi syndrome, Laurence-Moon-Biedl and Cohen syndrome, and febrile conditions (or had febrile conditions within the previous 2 months).

\subsection{Clinical Examination}

The following were performed on the studied groups of subjects:
1) Full history taking through clinical examination, with emphasis on any complications or medications;

2) Blood pressure measured according to American Heart Association guidelines;

3) Anthropometric indices: Body weight measured to the nearest $0.1 \mathrm{~kg}$ with a balance scale and height measured to the nearest $0.1 \mathrm{~cm}$. Body mass index was calculated as weight divided by height squared $\left(\mathrm{kg} / \mathrm{m}^{2}\right)$. Waist circumference (WC) was measured at the level midway between the lowest rib margin and the iliac crest. Hip circumference (HIP C) was measured at the widest level over the greater trochanters in a standing position by the same examiner; then waist to hip ratio (WHR) and Waist to height ratio (WHTR) were calculated [12]. Percentage body fat was calculated by the equation:

Child Body Fat $\%=(1.51 \times$ BMI $)-(0.70 \times$ Age $)-$ $(3.6 \times$ gender $)+1.4$ where $($ female $=0$ and male $=1)$ [13].

\subsection{Abdominal Ultrasonography}

In addition to the routine abdominal ultrasound examination based on the clinical indication, ultrasonography (US) distinctively quantifies visceral fat and subcutaneous fat. We measured the maximum preperitoneal visceral fat thickness (VFT) (Figure 1) and the minimum subcutaneous fat thickness (SFT) (Figure 2) by US. The visceral fat thickness (VFT) was measured by $3.5-5$ $\mathrm{MHz}$ convex-array probe. VFT is the distance between the internal surface of the abdominal surface of abdominal muscle and the anterior wall of the aorta $1 \mathrm{~cm}$ above the umbilicus. The thickness of subcutaneous fat was measured by $[14,15]$ placement of a $7.5-\mathrm{MHz}$ or $3.75-\mathrm{MHz}$ probe perpendicular to the skin on the epigastrium. Longitudinal scans are obtained along the middle line (linea Alba). The thickness of the subcutaneous fat is defined as the distance between the anterior surface of linea Alba and the fat-skin barrier [14,15].

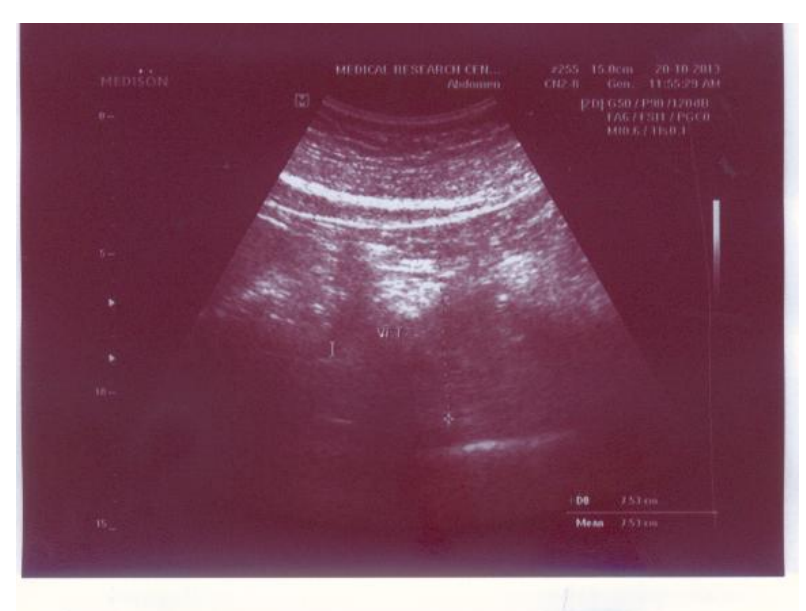

Figure 1. Visceral fat by ultrasonography. 


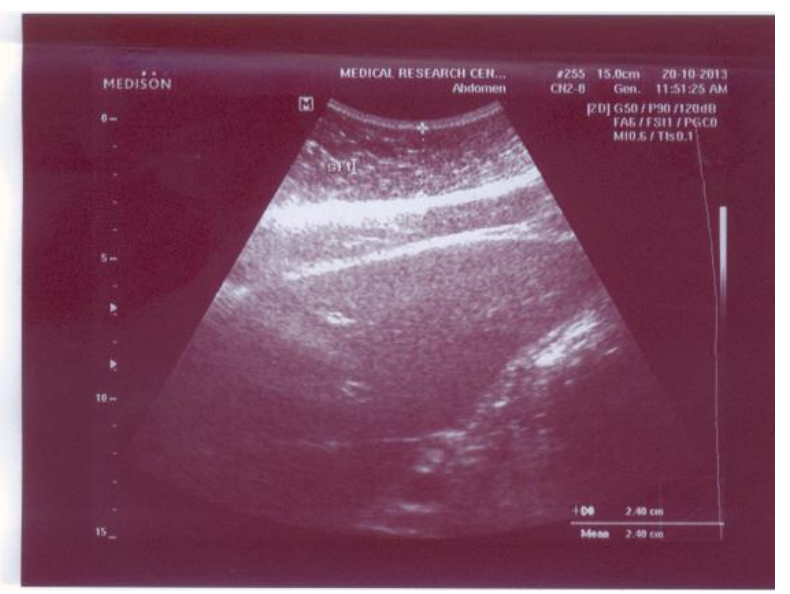

Figure 2. Subcutaneous fat by ultrasonography.

\subsection{The Laboratory Measurements}

Ten millimeters of venous blood were withdrawn under complete aseptic precautions from fasting subjects (12 $14 \mathrm{hrs})$. Samples were labeled and left to clot at room temperature for $15 \mathrm{~min}$ then centrifuged, sera were collected and aliquated for evaluation of the following parameters and inflammatory markers:

1) FBS \& Lipid profile were assessed by an OLYMPUS AU 400 Chemistry Analyzer.

2) Insulin and hsCRP levels were estimated by Enzyme immunoassay (ELISA).

3) Insulin resistance was calculated by the homeostasis model (HOMA-IR) using the following formula: HOMA$\mathrm{IR}=$ fasting insulin $(\mathrm{mU} / \mathrm{L}) \times$ fasting glucose $(\mathrm{mmoL} / \mathrm{L}) /$ 22.5 .

4) Serum IL-6 was assessed by Enzyme immunoassay (ELISA).

5) Serum progranulin was performed using Enzyme immunoassay (ELISA) [16].

\subsection{Statistical Analysis}

Each variable was assessed for a normal distribution. The standard computer program SPSS for Windows, release 12.0 (SPSS Inc., USA) was used for data entry and analysis. All numeric variables were expressed as mean \pm standard deviation (SD). The intergroup comparisons were performed by using an independent-sample t test and a one-way analysis of variance followed by Scheffe's post hoc test. Pearson's correlation tests $(r=$ correlation coefficient) were used for correlating normal. A linear regression analysis was obtained to calculate correlation coefficients. For all tests, a probability $(\mathrm{P})$ less than 0.05 $(<0.05)$ is considered significant.

\section{RESULTS}

Our results showed that among the obese individuals, 28
(56\%) were females and $22(44 \%)$ were males. There were no significant differences between obese subjects and control groups in terms of age or gender $(\mathrm{P}>0.05)$.

\subsection{Role of Gender}

Clinical and ultrasonography characteristics of the subjects by gender are listed in Table 1. No differences in all items were observed between the male and the female in normal weight group. Nevertheless, the girls had a higher WHR and WHR than did boys in obese group.

As regard the laboratory results (Table 2) no differences were observed between the boys and the girls in both groups.

\subsection{The Comparative Study between Obese and Normal Weight Children}

Our results of the comparative study are shown in Table 3. This revealed that there were significant differences between them as regards WHR, \%body fat $(\mathrm{P}=0.000)$. Serum cholesterol levels were significantly higher in obese children $(168.41 \pm 31.83 \mathrm{mg} / \mathrm{l})$ than in controls $(147.07 \pm 38.46 \mathrm{mg} / \mathrm{l}),(\mathrm{P}=0.024)$. The mean serum levels of LDLP were $(106.65 \pm 32.88 \mathrm{mg} / \mathrm{l}$ and $87.06 \pm$ $37.85 \mathrm{mg} / \mathrm{l}$ for obese and controls respectively, $\mathrm{P}=$ $0.034)$. Serum progranulin levels were significantly higher in obese children $(79.22 \pm 35.8 \mathrm{ng} / \mathrm{ml})$ than in controls $(96.82 \pm 19.61 \mathrm{ng} / \mathrm{ml}, \mathrm{P}<0.002)$. The mean serum IL6 level in the obese group was $(6.24 \pm 6.87 \mathrm{ng} / \mathrm{ml})$, which was higher than that in the non-obese group $(\mathrm{P}<0.03)$, in which the mean serum IL6 level was $(3.61 \pm 2.24$ $\mathrm{ng} / \mathrm{ml}$ ). Regarding the subcutaneous fat thickness (SFT), we found that there was more fat in the obese group , showing a significant difference from the control group (P-value $<0.05$ ). Visceral fat thickness (VFT) mean levels were significantly higher in obese children $(3.65 \pm$ $1.26 \mathrm{~cm})$ than in controls $(2.83 \pm 1.27 \mathrm{~cm}, \mathrm{P}<0.008)$.

\subsection{The Laboratory Data within the Visceral Fat Thickness Tertiles}

Table 4 shows the laboratory data within the visceral fat thickness tertiles. The subjects were classified by the tertile on the basis of their VFT. Mean values of serum progranulin for tertiles of visceral fat thickness were $<3.40 \mathrm{~cm}$ (low tertile), $3.41-4.16 \mathrm{~cm}$ (middle tertile), and $\geq 4.17 \mathrm{~cm}$ (high tertile) Figure 3 . Serum progranulin increased from the low tertile to the middle tertile and the high tertile. The mean serum progranulin in the high tertile group were significantly higher than those in the low tertile and middle tertile groups (one-way ANOVA followed by Scheffe's post hoc test): $\mathrm{P}=0.030$ and $\mathrm{P}=$ 0.039 respectively. 
Table 1. Clinical and ultrasonography characteristics of the subjects by gender.

\begin{tabular}{|c|c|c|c|c|c|c|c|}
\hline & \multirow{2}{*}{$\begin{array}{c}\text { Gender } \\
1=\text { Male } 0=\text { Female }\end{array}$} & \multicolumn{3}{|c|}{ Normal Weight Children } & \multicolumn{3}{|c|}{ Obese Children } \\
\hline & & Mean & Std. Deviation & Sig. (2-tailed) & Mean & Std. Deviation & Sig. (2-tailed) \\
\hline \multirow{2}{*}{ BMI } & 1 & 20.57 & 2.58 & \multirow{2}{*}{ NS } & 31.51 & 3.98 & \multirow{2}{*}{ NS } \\
\hline & 0 & 20.05 & 3.52 & & 31.25 & 4.84 & \\
\hline \multirow{2}{*}{ WHTR } & 1 & 0.49 & 0.08 & \multirow{2}{*}{ NS } & 0.64 & 0.11 & \multirow{2}{*}{0.04} \\
\hline & 0 & 0.47 & 0.07 & & 0.60 & 0.06 & \\
\hline \multirow{2}{*}{ WHR } & 1 & 0.87 & 0.08 & \multirow{2}{*}{ NS } & 0.92 & 0.07 & \multirow{2}{*}{0.00} \\
\hline & 0 & 0.84 & 0.07 & & 0.86 & 0.06 & \\
\hline \multirow{2}{*}{$\mathrm{BF} \%$} & 1 & 21.47 & 5.24 & \multirow{2}{*}{ NS } & 36.38 & 5.22 & \multirow{2}{*}{ NS } \\
\hline & 0 & 22.19 & 4.68 & & 36.62 & 9.24 & \\
\hline \multirow{2}{*}{$\begin{array}{c}\text { SBP } \\
{[\mathrm{mm} \mathrm{Hg}]}\end{array}$} & 1 & 104.00 & 8.10 & \multirow{2}{*}{ NS } & 113.39 & 11.87 & \multirow{2}{*}{ NS } \\
\hline & 0 & 102.69 & 13.94 & & 107.50 & 13.29 & \\
\hline \multirow{2}{*}{$\begin{array}{c}\text { DBP } \\
{[\mathrm{mm} \mathrm{Hg}]}\end{array}$} & 1 & 65.00 & 8.50 & \multirow{2}{*}{ NS } & 70.89 & 7.94 & \multirow{2}{*}{ NS } \\
\hline & 0 & 65.00 & 7.07 & & 67.08 & 8.49 & \\
\hline \multirow{2}{*}{$\mathrm{SFT}[\mathrm{cm}]$} & 1 & 1.11 & 0.55 & \multirow{2}{*}{ NS } & 1.81 & 0.64 & \multirow{2}{*}{ NS } \\
\hline & 0 & 1.48 & 0.69 & & 2.01 & 0.62 & \\
\hline \multirow{2}{*}{ VFT $[\mathrm{cm}]$} & 1 & 2.93 & 1.50 & \multirow{2}{*}{ NS } & 4.13 & 1.57 & \multirow{2}{*}{ NS } \\
\hline & 0 & 2.73 & 1.03 & & 3.85 & 1.34 & \\
\hline
\end{tabular}

BMI — body mass index, WHTR — waist height ratio, WHR — waist hip ratio, BF\%—body fat percentage, SBP — systolic blood pressure, DBP — diastolic blood pressure, SFT — subcutaneous fat thickness, VFT—visceral fat thickness.

Table 2. Laboratory characteristics of the subjects by gender.

\begin{tabular}{|c|c|c|c|c|c|c|c|}
\hline & \multirow{2}{*}{$\frac{\text { Gender }}{1=\text { Male } 0=\text { Female }}$} & \multicolumn{3}{|c|}{ Normal Weight Children } & \multicolumn{3}{|c|}{ Obese Children } \\
\hline & & Mean & Std. Deviation & Sig. (2-tailed) & Mean & Std. Deviation & Sig. (2-tailed) \\
\hline \multirow{2}{*}{$\begin{array}{l}\mathrm{FBG} \\
{[\mathrm{mg} / \mathrm{l}]}\end{array}$} & 1 & 86.50 & 10.51 & \multirow[b]{2}{*}{ NS } & 86.50 & 11.69 & \multirow{2}{*}{ NS } \\
\hline & 0 & 85.41 & 10.62 & & 88.92 & 13.27 & \\
\hline \multirow{2}{*}{$\begin{array}{l}\text { INSULIN } \\
{[\mathrm{mU} / \mathrm{l}]}\end{array}$} & 1 & 9.79 & 6.23 & \multirow{2}{*}{ NS } & 12.07 & 7.96 & \multirow{2}{*}{ NS } \\
\hline & 0 & 11.28 & 7.70 & & 12.55 & 6.14 & \\
\hline \multirow{2}{*}{ HOMA-IR } & 1 & 2.06 & 1.34 & \multirow{2}{*}{ NS } & 3.77 & 2.40 & \multirow{2}{*}{ NS } \\
\hline & 0 & 2.32 & 1.59 & & 2.89 & 1.53 & \\
\hline \multirow{2}{*}{$\begin{array}{c}\text { PROGNULIN } \\
\mathrm{ng} / \mathrm{mL}\end{array}$} & 1 & 50.77 & 47.18 & \multirow{2}{*}{ NS } & 54.70 & 42.54 & \multirow{2}{*}{ NS } \\
\hline & 0 & 30.16 & 37.17 & & 38.91 & 29.98 & \\
\hline \multirow{2}{*}{$\mathrm{hsCRP}[\mathrm{mg} / \mathrm{l}]$} & 1 & 3.77 & 4.34 & \multirow{2}{*}{ NS } & 6.89 & 5.44 & \multirow{2}{*}{ NS } \\
\hline & 0 & 5.85 & 6.34 & & 9.81 & 8.13 & \\
\hline \multirow{2}{*}{$\begin{array}{c}\text { CHOLESTEROL } \\
{[\mathrm{mg} / \mathrm{l}]}\end{array}$} & 1 & 139.87 & 29.59 & \multirow[t]{2}{*}{ NS } & 164.35 & 33.35 & \multirow{2}{*}{ NS } \\
\hline & 0 & 154.27 & 45.57 & & 166.46 & 33.12 & \\
\hline \multirow{2}{*}{$\begin{array}{c}\text { TRIGLYCERIDE } \\
{[\mathrm{mg} / \mathrm{l}]}\end{array}$} & 1 & 99.40 & 42.88 & \multirow{2}{*}{ NS } & 107.85 & 63.35 & \multirow{2}{*}{ NS } \\
\hline & 0 & 86.87 & 31.73 & & 85.18 & 30.16 & \\
\hline \multirow{2}{*}{ HDLP [mg/l] } & 1 & 45.25 & 22.04 & \multirow{2}{*}{ NS } & 50.75 & 30.63 & \multirow{2}{*}{ NS } \\
\hline & 0 & 35.67 & 8.50 & & 43.13 & 11.87 & \\
\hline \multirow{2}{*}{$\operatorname{LDLP}[\mathrm{mg} / \mathrm{l}]$} & 1 & 76.88 & 25.60 & \multirow{2}{*}{ NS } & 100.42 & 28.39 & \multirow{2}{*}{ NS } \\
\hline & 0 & 97.93 & 46.07 & & 104.16 & 32.13 & \\
\hline \multirow{2}{*}{ IL6 ng/ml } & 1 & 3.29 & 1.56 & \multirow{2}{*}{ NS } & 8.80 & 9.01 & \multirow{2}{*}{ NS } \\
\hline & 0 & 3.91 & 2.75 & & 7.35 & 7.51 & \\
\hline
\end{tabular}

FBG_-fasting blood glucose, HOMA-IR — homeostasis model of Insulin resistance, HDLP—high density lipoprotein, LDLP_-low density lipoprotein, IL6 interleukin 6. 
Table 3. Clinical and ultrasonography characteristics of the subjects (normal weight and obese).

\begin{tabular}{|c|c|c|c|c|}
\hline & $1=$ Non-obese $2=$ Obese & Mean & Std. Deviation & Sig. (2-tailed) \\
\hline \multirow[b]{2}{*}{ AGE [year] } & 1 & 11.63 & 3.97 & \multirow[b]{2}{*}{ NS } \\
\hline & 2 & 13.13 & 5.18 & \\
\hline \multirow{2}{*}{ WHTR } & 1 & 0.48 & 0.07 & \multirow{2}{*}{0.000} \\
\hline & 2 & 0.59 & 0.05 & \\
\hline \multirow[b]{2}{*}{ WHR } & 1 & 0.86 & 0.08 & \multirow[b]{2}{*}{ NS } \\
\hline & 2 & 0.89 & 0.07 & \\
\hline \multirow{2}{*}{$\mathrm{BF} \%$} & 1 & 21.83 & 4.91 & \multirow{2}{*}{0.000} \\
\hline & 2 & 32.78 & 7.89 & \\
\hline \multirow{2}{*}{$\begin{array}{c}\mathrm{S} \mathrm{BP} \\
{[\mathrm{mm} \mathrm{Hg}]}\end{array}$} & 1 & 103.26 & 11.54 & \multirow{2}{*}{ NS } \\
\hline & 2 & 106.22 & 12.03 & \\
\hline \multirow{2}{*}{$\begin{array}{c}\text { D BP } \\
{[\mathrm{mm} \mathrm{Hg}]}\end{array}$} & 1 & 65.00 & 7.54 & \multirow{2}{*}{ NS } \\
\hline & 2 & 65.98 & 7.00 & \\
\hline \multirow{2}{*}{ FBG $[\mathrm{mg} / \mathrm{l}]$} & 1 & 85.97 & 10.42 & \multirow{2}{*}{ NS } \\
\hline & 2 & 87.46 & 10.17 & \\
\hline \multirow{2}{*}{$\begin{array}{c}\text { INSULIN } \\
{[\mathrm{mU} / \mathrm{l}]}\end{array}$} & 1 & 10.54 & 6.95 & \multirow{2}{*}{ NS } \\
\hline & 2 & 9.64 & 4.57 & \\
\hline \multirow{2}{*}{ HOMA-IR } & 1 & 2.63 & 1.40 & \multirow{2}{*}{0.023} \\
\hline & 2 & 3.28 & 1.78 & \\
\hline \multirow{2}{*}{$\begin{array}{l}\text { hsCRP } \\
{[\mathrm{mg} / \mathrm{l}]}\end{array}$} & 1 & 3.133 & 5.46 & \multirow{2}{*}{0.003} \\
\hline & 2 & 7.86 & 8.12 & \\
\hline \multirow{2}{*}{$\begin{array}{c}\text { CHOLESTEROL } \\
{[\mathrm{mg} / \mathrm{l}]}\end{array}$} & 1 & 147.07 & 38.46 & \multirow{2}{*}{0.024} \\
\hline & 2 & 168.41 & 31.83 & \\
\hline \multirow{2}{*}{$\begin{array}{l}\text { TRIGLYCERYDE } \\
{[\mathrm{mg} / \mathrm{l}]}\end{array}$} & 1 & 93.13 & 37.61 & \multirow{2}{*}{ NS } \\
\hline & 2 & 84.69 & 33.74 & \\
\hline \multirow{2}{*}{$\begin{array}{l}\text { HDLP } \\
{[\mathrm{mg} / 1]}\end{array}$} & 1 & 40.61 & 17.33 & \multirow{2}{*}{ NS } \\
\hline & 2 & 47.94 & 24.85 & \\
\hline \multirow{2}{*}{$\begin{array}{l}\text { LDLP } \\
{[\mathrm{mg} / 1]}\end{array}$} & 1 & 87.06 & 37.85 & \multirow{2}{*}{0.034} \\
\hline & 2 & 106.65 & 32.88 & \\
\hline PROGRANULIN & 1 & 30.18 & 23.82 & 0.025 \\
\hline $\mathrm{ng} / \mathrm{mL}$ & 2 & 48.87 & 42.33 & 0.020 \\
\hline IL6 & 1 & 3.61 & 2.24 & 0021 \\
\hline $\mathrm{ng} / \mathrm{ml}$ & 2 & 6.24 & 6.87 & \\
\hline SET [ $\mathrm{cm}$ & 1 & 1.28 & 0.64 & - \\
\hline ST I [ [ [111] & 2 & 1.84 & 0.67 & 0.001 \\
\hline VFT & 1 & 2.83 & 1.27 & 0008 \\
\hline$[\mathrm{cm}]$ & 2 & 3.65 & 1.26 & 0.000 \\
\hline
\end{tabular}

BMI-body mass index, WHTR — waist height ratio, WHR — waist hip ratio, FBG-fasting blood glucose, HOMA-IR-homeostasis model of Insulin resistance, HDLP - high density lipoprotein, LDLP-low density lipoprotein, IL6 - interleukin 6. 
Table 4. Laboratory data within the visceral fat thickness tertiles.

\begin{tabular}{|c|c|c|c|c|c|c|c|c|}
\hline \multirow[t]{2}{*}{ laboratory data } & \multirow{2}{*}{$\frac{\text { VFT tertiles }}{1}$} & \multicolumn{2}{|c|}{ Mean SD } & \multirow[t]{2}{*}{ Sig. } & & \multicolumn{2}{|c|}{ Mean SD } & \multirow[t]{2}{*}{ Sig. } \\
\hline & & 34.02 & 38.40 & & & 160.88 & 35.97 & \\
\hline \multirow[t]{3}{*}{ PGRNULIN( $\left({ }^{*}\right)$} & 2 & 35.95 & 26.93 & 0.03 & CHOLESTEROL & 151.50 & 36.07 & NS \\
\hline & 3 & 79.79 & 52.40 & & & 169.69 & 23.89 & \\
\hline & 1 & 88.15 & 7.79 & & & 87.69 & 39.14 & \\
\hline \multirow[t]{3}{*}{ FBG } & 2 & 81.73 & 9.87 & NS & TRIGLYCERIDE & 106.60 & 61.23 & NS \\
\hline & 3 & 90.12 & 18.86 & & & 107.69 & 58.34 & \\
\hline & 1 & 9.79 & 5.21 & & & 50.17 & 31.67 & \\
\hline \multirow[t]{3}{*}{ INSULIN } & 2 & 13.69 & 6.89 & NS & HDLP & 44.55 & 16.58 & NS \\
\hline & 3 & 13.86 & 8.05 & & & 40.85 & 8.95 & \\
\hline & 1 & 1.33 & 1.39 & & & 100.88 & 35.05 & \\
\hline \multirow[t]{3}{*}{ HOMA-IR } & 2 & 2.04 & 1.13 & NS & LDLP & 87.73 & 26.74 & NS \\
\hline & 3 & 3.59 & 1.89 & & & 108.54 & 24.38 & \\
\hline & 1 & 7.57 & 5.30 & & & 4.56 & 4.23 & \\
\hline \multirow[t]{2}{*}{ hsCRP } & 2 & 8.66 & 8.03 & NS & IL6 & 7.96 & 9.07 & NS \\
\hline & 3 & 11.63 & 9.38 & & & 10.06 & 10.07 & \\
\hline
\end{tabular}

Mean values for tertiles of visceral fat thickness were $<3.40 \mathrm{~cm}$ (low tertile), $3.41-4.16 \mathrm{~cm}$ (middle tertile), and $\geq 4.17 \mathrm{~cm}$ (high tertile). $\left({ }^{*}\right.$ ), $1,3-2,3$ Significantly different (one-way ANOVA followed by Scheffe's post hoc test): $\mathrm{P}<0.30$ and $\mathrm{P}<0.039$ and respectively.

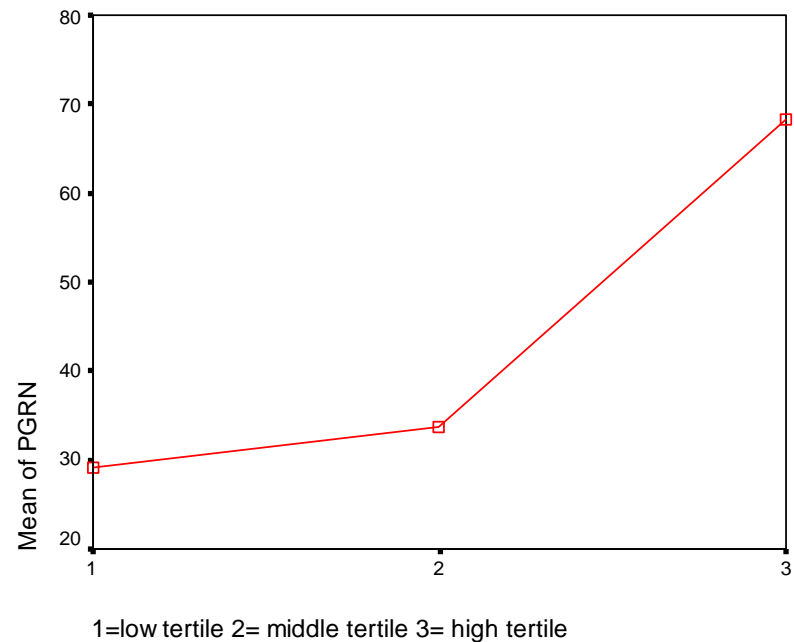

Figure 3. Mean values of serum progranulin for tertiles of visceral fat thickness.

\subsection{Correlation between the Ultrasonography Values and the Laboratory Data}

The correlation coefficients between the ultrasonography values and the laboratory data are shown in Table 5. It was found that serum progranulin among children was highly positively correlated to visceral fat thickness, IL6, Insulin and IHOMA-IR $(\mathrm{P}=0.000,0.007,0.001$ and
0.006 respectively). VFT was highly positively correlated to progranulin, SFT, IL6, insulin, HOMA-IR and hsCRP $(\mathrm{P}=0.001,0.000,0.001,0.001,0.003$ and 0.003). However, the correlation coefficients between SFT, progranulin and IL6 were lower than those shown with VFT. Figure 4 shows correlation between progranulin and visceral fat thickness in obese children.

\section{DISCUSSION}

To the best of our knowledge, this is the first study analyzing the cross-sectional relationships between progranulin, insulin resistance, inflammatory markers and visceral fat in childhood obesity.

As regard serum progranulin no statistical difference was observed between the boys and the girls in both normal weight and obese children. So, serum progranulin concentrations were independent of gender. Our results showed that progranulin serum concentrations were significantly higher in obese children as compared to controls, in concordance with a study in adults [17].

Body fat distribution varies considerably, even among people with similar total fat amounts. It is well known that visceral obesity may be a better predictor of metabolic syndrome-including hyperinsulinemia, glucose intolerance, dyslipidemia, and CVD - and cancer than may general obesity [6,7]. Previous studies reported that ultrasonography could be used to estimate visceral 


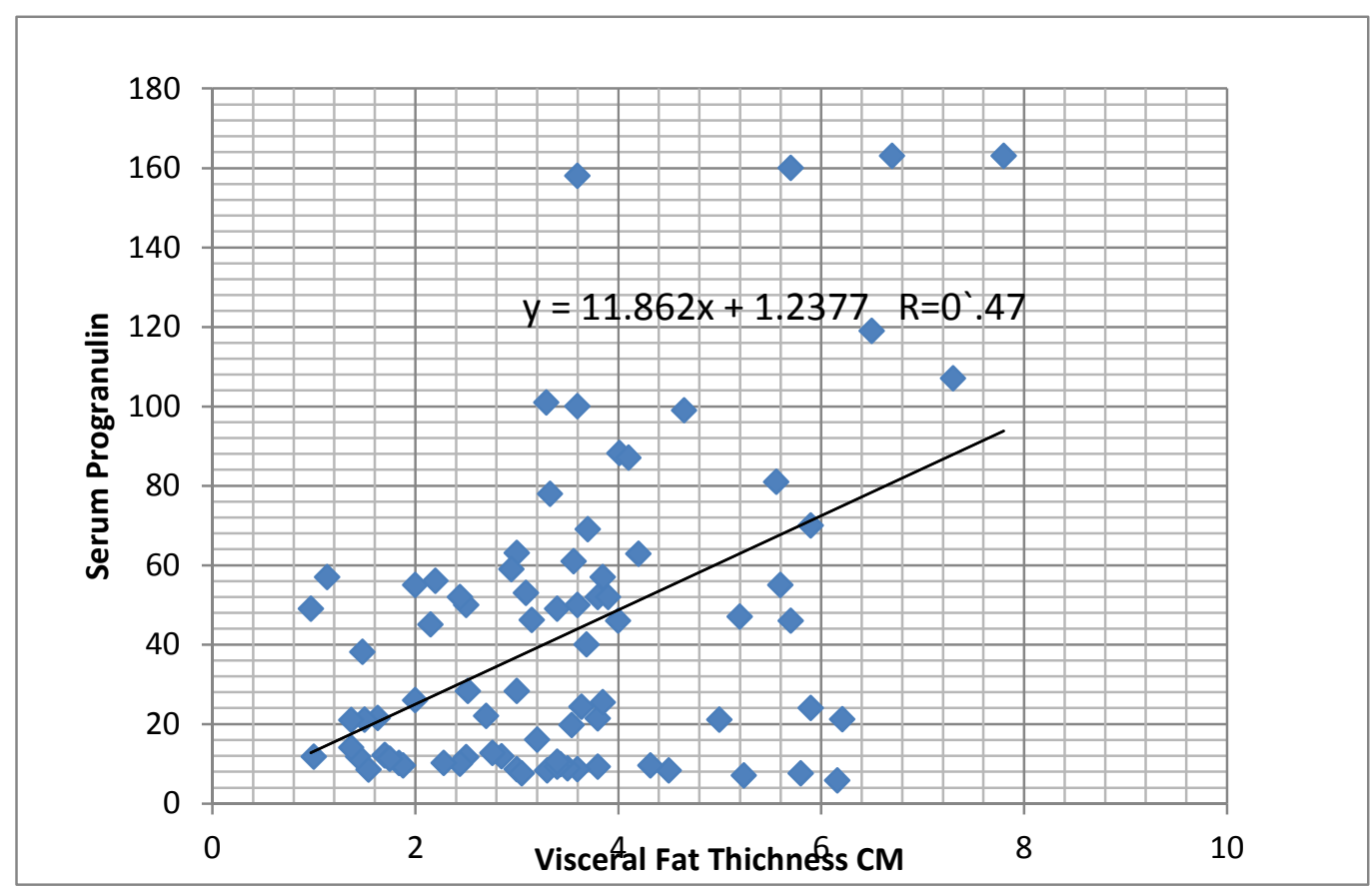

Figure 4. Correlation between progranulin and visceral fat thickness in obese children.

Table 5. Correlations between several ultrasonography values and laboratory data.

\begin{tabular}{cccccccccc}
\hline & PROGRNULIN & V FT & SFT & IL6 & INSULIN & HOMA-IR & hsCRP \\
\hline PROGRANULIN & $\begin{array}{c}\text { Pearson } \\
\text { Correlation }\end{array}$ & 1 & $0.475\left(^{* *}\right)$ & 0.241 & $0.368\left(^{* *}\right)$ & $0.440\left(^{* *}\right)$ & $0.379\left(^{* *}\right)$ & 0.257 \\
& $\begin{array}{c}\text { Sig. (2-tailed) } \\
\text { Visceral Fat }\end{array}$ & 0 & 0.001 & 0.129 & 0.007 & 0.001 & 0.006 & 0.066 \\
& $\begin{array}{c}\text { Pearson } \\
\text { Correlation } \\
\text { Sig. (2-tailed) }\end{array}$ & $0.475\left(^{* *}\right)$ & 1 & $0.494\left(^{* *}\right)$ & $0.476\left(^{* *}\right)$ & $0.478\left(^{* *}\right)$ & $0.439\left(^{* *}\right)$ & $0.437\left(^{* *}\right)$ \\
& $\begin{array}{c}\text { Pearson } \\
\text { SCF }\end{array}$ & 0.001 & 0 & 0.000 & 0.001 & 0.001 & 0.003 & 0.003 \\
& $\begin{array}{c}\text { Correlation } \\
\text { Sig. (2-tailed) }\end{array}$ & 0.129 & $0.494\left(^{* *}\right)$ & 1 & 0.238 & 0.278 & $0.351\left(^{*}\right)$ & $0.342\left(^{*}\right)$ \\
& & 0.000 & 0. & 0.134 & 0.075 & 0.025 & 0.027 \\
\hline
\end{tabular}

${ }^{* *}$ Correlation is significant at the 0.01 level (2-tailed). ${ }^{*}$ Correlation is significant at the 0.05 level (2-tailed).

adiposity $[15,18]$. This study suggested that a VFT of $3.41-4.16 \mathrm{~cm}$ was the middle tertile, and $\geq 4.17 \mathrm{~cm}$ was the high tertile in Egyptian children.

Serum progranulin among children was highly positively correlated to visceral fat thickness, IL6, Insulin and IHOMA-IR. PGRN is a key adipokine that mediates insulin resistance in obesity through production of IL-6 in adipose tissue. IL-6 has been reported to induce insulin resistance through JAK/STAT signaling and suppression of cytokine signaling-3 (SOCS3) in both adipocytes and hepatocytes [19-21]. These results indicate that PGRN promotes IL-6 expression in adipocytes and suggest that the resultant increase in IL-6 enhances SOCS3 expression through activating JAK-STAT signaling, leading to insulin resistance in adipocytes. Accordingly, PGRN may well participate in chronic inflammation associated with insulin resistance and obesity.
Individuals with peripheral obesity, i.e. fat distributed subcutaneously are at little risk of the common medical complications of obesity, whereas individuals with central obesity, i.e. fat accumulated in visceral depots, are very much prone to these complications [22]. In obese patients, it was shown that stromal cells from the subcutaneous adipose tissue region proliferated faster than those from intra-abdominal visceral fat depots [23]. Recently, Gealekman et al. reported that subcutaneous adipose tissue has a higher capillary density per adipocyte and higher angiogenic growth capacity compared with visceral tissue [24]. The results support the existence of qualitative differences in angiogenic expandability between subcutaneous and visceral adipose tissue [24]. Progranulin is an inducible protein in response to hypoxia or acidosis. This may explain the differences between correlation of VFT and SFT and circulating 
markers of inflammation progranulin and IL6 in our obese patients.

This study had some limitations. First, it was performed only in an Egyptian population, the VFT cutoffs differ from those in other ethnic groups. Second, this study did not analyze the role of puberty although it may affect IR.

In conclusion, we demonstrated for the first time that serum PGRN concentrations increased in Egyptian obese children. The concentrations of serum PGRN correlated closely with visceral fat, insulin, insulin resistance and IL6. Suggesting PGRN may contribute to the pathogenesis of chronic inflammation in obesity. It could be a novel marker of visceral fat in obesity. Thus PGRN could be a potential therapeutic target for management of chronic inflammation in obesity.

\section{ACKNOWLEDGEMENTS}

The study was a part of a project supported financially by Science and Technology Development Fund (STDF) Egypt, grant no.2973.

\section{REFERENCES}

[1] G Ogden, C.L., Carroll, M.D., Kit, B.K. and Flegal, K.M. (2012) Prevalence of obesity and trends in body mass index among US children and adolescents, 1999-2010. Journal of the American Medical Association, 307, 483490. http://dx.doi.org/10.1001/jama.2012.40

[2] Mariusz, S. , Rafał, N.W., Marek, P., et al. (2012) Serum concentrations of adiponectin, leptin, resistin, ghrelin and insulin and their association with obesity indices in obese normo- and hypertensive patients-Pilot study. Archives of Medical Science, 8, 431-436.

[3] Recio-Rodriguez, J.I., Gomez-Marcos, M.A., PatinoAlonso, M.C., Agudo-Conde, C., Rodriguez-Sanchez, E., Garcia-Ortiz, L. and Vasorisk, G. (2012) Abdominal obesity vs general obesity for identifying arterial stiffness, subclinical atherosclerosis and wave reflection in healthy, diabetics and hypertensive. BMC Cardiovascular Disorders, 12, 3-11. http://dx.doi.org/10.1186/1471-2261-12-3

[4] Zúñiga, L.A., Shen, W.J. and Joyce-Shaikh, B., et al. (2010) IL-17regulates adipogenesis, glucose homeostasis, and obesity. Journal of Immunology, 85, 6947-6959. http://dx.doi.org/10.4049/jimmunol.1001269

[5] Fain, J.N. (2006) Release of interleukins and other inflammatory cytokines by human adipose tissue is enhanced in obesity and primarily due to the nonfat cells. Vitamins \& Hormones, 74, 443-477.

[6] Blüher, M. (2008) the inflammatory process of adipose tissue. Pediatric Endocrinology Reviews, 6, 24-31.

[7] Ye, J.P. (2009) Emerging role of adipose tissue hypoxia in obesity and insulin resistance. International Journal of Obesity, 33, 54-66. http://dx.doi.org/10.1038/ijo.2008.229

[8] Daniel, E.D., He, Z. and Bateman, A. (2003) Progranulin (acrogranin/PC cell-derived growth factor/granulin-epithelin precursor) is expressed in the placenta, epidermis, microvasculature, and brain during murine development. Developmental Dynamics, 227, 593-599. http://dx.doi.org/10.1002/dvdy.10341

[9] He, Z. and Bateman, A. (2003) Progranulin (granulinepithelin precursor, PC-cell-derived growth factor, acrogranin) mediates tissue repair and tumorigenesis. Journal of Molecular Medicine, 81, 600-612. http://dx.doi.org/10.1007/s00109-003-0474-3

[10] Guerra, R.R., Kriazhev, L., Hernandez-Blazquez, F.J. and Bateman, A. (2007) Progranulin is a stress-response factor in fibroblasts subjected to hypoxia and acidosis. Growth Factors, 25, 280-285. http://dx.doi.org/10.1080/08977190701781222

[11] Egyptian growth curves (2009) Diabetes endocrine metabolism pediatric unit Cairo university children's hospital. http://dempuegypt.blogspot.com/

[12] Ismail, N.A., Ragab, S., Abd El Dayem, S.A., Abd ElBaky, A., et al. (2012) Fetuin-A levels in obesity: Differences in relation to metabolic syndrome and correlation with clinical and laboratory variables. Archives of Medical Science, 8, 826-833. http://dx.doi.org/10.5114/aoms.2012.31616

[13] Deurenberg, P., Weststrate, J.A. and Seidell, J.C. (1991) Body mass index as a measure of body fatness: Age- and sex-specific prediction formulas. The British Journal of Nutrition, 65, 105-114. http://dx.doi.org/10.1079/BJN19910073

[14] Wafaa, M.A., Ragab, R., Ismail, N.A., Yasser, Elhosary, A., et al. (2012) Frequency of non-alcoholic fatty liver disease in overweight/obese children and adults: Clinical, sonographic picture and biochemical assessment. Journal of Genetic Engineering and Biotechnology, 10, 221-227.

[15] Kim, S.K., Kim, H.J., Hur, K.Y., et al. (2004) Visceral fat thickness measured by ultrasonography can estimate not only visceral obesity but also risks of cardiovascular and metabolic Diseases. American Journal of Clinical Nutrition, 79, 593-599.

[16] Toshiya, M., Ayako, M., Kohtaro, M., et al. (2012) Progranulin is a key adipokine mediating high fat diet-induced insulin resistance and obesity through IL-6 in adipose tissue. Cell Metabolism, 15, 38-50. http://dx.doi.org/10.1016/j.cmet.2011.12.002

[17] Tönjes, A., Fasshauer, M., Kratzsch, J. and Stumvoll, M., Blüher, M. (2010) Adipokine pattern in subjects with impaired fasting glucose and impaired glucose tolerance in comparison to normal glucose tolerance and diabetes. PLOS ONE, 5, e13911. http://dx.doi.org/10.1371/journal.pone.0013911

[18] Fujioka, S., Matsuzawa, Y., Tokunaga, K. and Tarui, S. (1987) Contribution of intra-abdominal fat accumulation to the impairment of glucose and lipid metabolism in human obesity. Metabolism, 36, 54-59.

[19] Ribeiro-Filho, F.F., Faria, A.N., Kohlmann Jr., O., et al. (2001) Ultrasonography for the evaluation of visceral fat and cardiovascular risk. Hypertension, 38, 713-717. http://dx.doi.org/10.1161/01.HYP.38.3.713

[20] Howard, J.K. and Flier, J.S. (2006) Attenuation of leptin and insulin signaling by SOCS proteins. Trends in Endocrinology \& Metabolism, 17, 365-371. 
http://dx.doi.org/10.1016/j.tem.2006.09.007

[21] Rotter, V., Nagaev, I. and Smith, U. (2003) Interleukin-6 (IL-6) induces insulin resistance in 3T3-L1 adipocytes and is, like IL-8 and tumor necrosis factor-a, overexpressed in human fat cells from insulin-resistant subjects. Journal of Biological Chemistry, 278, 45777-45784. http://dx.doi.org/10.1074/jbc.M301977200

[22] Blüher, M. (2013) Adipose tissue dysfunction contributes to obesity related metabolic diseases. Best Practice \& Research Clinical Endocrinology \& Metabolism, 27, 163-
177.

[23] Van Harmelen, V., Röhrig, K. and Hauner, H. (2004) Comparison of proliferation and differentiation capacity of human adipocyte. Metabolism, 53, 632-637.

[24] Gealekman, O., Guseva, N., Hartigan, C., et al. (2011) Depot-specific differences and insufficient subcutaneous adipose tissue angiogenesis in human obesity. Circulation, 123, 186-194.

http://dx.doi.org/10.1161/CIRCULATIONAHA.110.9701 45

\section{List of Abbreviations}

progranulin (PGRN); high sensitivity reactive protein (hsCRP); homeostasis model of Insulin resistance (HOMAIR); visceral fat thickness (VFT); subcutaneous fat thickness (SFT); adipose tissue hypoxia (ATH); body mass index (BMI); Waist circumference (WC); hip circumference (HIP C); waist to hip ratio (WHR); waist to height ratio (WHTR); body fat percentage (BF \%); high density lipoprotein (HDLP); low density lipoprotein LDLP-(LDLP): interleukin 6 (IL6); fasting blood glucose (FBG); suppression of cytokine signaling-3 (SOCS3). 